\title{
Superação no esporte: limites individuais ou sociais?
}

\author{
M. Lúcia Silva \\ Katia Rubio
}

https://doi.org/10.5628/rpcd.03.03.69

\section{RESUMO}

A superação é um termo recorrente na história de vida de atletas brasileiros medalhistas olímpicos. Esses atletas referem em grande parte de seus discursos a importância de terem persistido, perseverado e buscado caminhos alternativos às dificuldades impostas ao longo da carreira para construir uma trajetória vitoriosa. A esse resultado na solução de problemas é dado o nome de superação. O que faz um atleta romper barreiras, alcançando o que às vezes parece ser impossível, é um conjunto de fatores técnicos, físicos, materiais e psicológicos que, quando bem trabalhados, ampliam muito os seus limites. O objetivo deste trabalho é refletir como a superação de limites individuais e sociais está presente na vida do atleta de alto nível. Quais os motivos que levam um homem ou mulher a se interessar pelo esporte, chegando a tornar-se atletas de alto rendimento, que limites necessitam ou desejam vencer, como o recorde, o doping e a derrota se inserem nesta trajetória de superar barreiras, são questões que serão aqui abordadas por meio de uma revisão bibliográfica.

Palavras-chave: esporte, superação, recorde, doping, derrota.

\author{
Escola de Educação Física e Esporte \\ Universidade de São Paulo, Brasil
}

\begin{abstract}
Overcoming in Sport: Individual or social limits?

Overcome is a recurrent term in the life history of Brazilian athletes winners of medals in Olympic Games. In their life history reports' they emphasize the importance of having persisted, persevered and discovered alternative ways in overcoming the difficulties imposed by their long sport careers. To this problem solving is given the name overcome. What makes an athlete overcome obstacles achieving performances that sometimes seem to be impossible is a set of technical, physical, material and psychological factors that, when well trained, enlarge his limits. The purpose of this review is to consider how the overcome of individual and social limits is present in the life of high performance athletes. Which motives make a man or woman to fulfil in sport and to become a high performance athlete; which limits are required in their desire to win, to perform, to dope and cope with defeat so that they follow this path to overcome obstacles, are matters that will be broached here through literature review.
\end{abstract}

Key Words: sport, overcome, record, doping, defeat. 


\section{INTRODUÇÃO}

Os gregos treinavam para se adaptar à sua civilização; nós treinamo-nos para suportar a nossa.

Jean Prévost

Ouve-se com certa freqüência a afirmação "que o esporte hoje não é mais como era antigamente". Desde o surgimento de atividades físicas com a finalidade de competição até aos grandes espetáculos dos dias atuais, o esporte viveu inúmeras transformações. O ideal esportivo do atleta grego antigo não é o mesmo do atleta moderno, que não é igual ao do atleta contemporâneo. Além da mudança de valores, a própria prática da modalidade - técnicas esportivas, equipamentos, regras - tem sido alterada. O esporte acompanha par e passo as transformações que ocorrem na sociedade, refletindo em seu ambiente os avanços científicos, tecnológicos e os valores criados e desenvolvidos pelos indivíduos. Porém, superação é um termo recorrente quando se trata do universo esportivo seja na Idade Antiga, seja nos tempos atuais. Na Carta Olímpica(4) o lema Citius, Altius, Fortius (p.18) escrito pelo Barão de Coubertin, inspirado nos valores dos Jogos Olímpicos Helênicos, expressa a mensagem que o Comitê Olímpico Internacional dirige aos atletas de todo o mundo, convidando-os a superar-se de acordo com o espírito olímpico. Mesmo diante das muitas transformações ocorridas ao longo do último século no ambiente esportivo, o espírito de superação ainda perdura como um dos valores morais mais preciosos do esporte e segundo Coubertin (14) esta "busca do perfeccionismo" é essencial.

Tratando do esclarecimento quanto à qualidade da superação, um outro conceito emerge dessa discussão que pode ser denominado como limite.

Conhecer o limite que se apresenta no momento em que ele é vivido, para poder superá-lo adiante, é uma constante nas narrativas de atletas de alto rendimento, inclusive dos medalhistas olímpicos brasileiros, insinuando que na realização esportiva o máximo está sempre a ser alcançado.

Sendo muito constante no discurso de atletas o relato da transposição de obstáculos ao longo da carreira esportiva, esta revisão tem como objetivo refletir o que representa a superação e como ela é vivida pelos atletas de alto nível. Quais os motivos que levam um homem ou mulher a se interessar pelo esporte, chegando a torna-se um atleta de rendimento, que limites necessitam ou desejam vencer, como o recorde, o doping e a derrota se inserem nesta trajetória de superar barreiras são questões aqui abordadas. Assim como no discurso dos atletas, vários autores utilizam o termo superação para designar atitudes fora do comum $(2,11,17,22)$. Apesar desse assunto mostrar-se presente no âmbito esportivo, foram poucos os estudiosos que se dedicaram a discuti-lo na sua especificidade.

\section{RECORDE}

Os Jogos Helênicos tinham no esporte um meio de desenvolver o físico e a moral. Os gregos não tinham como preocupação primeira a superação dos tempos, das distâncias, dos pesos ou pontos para se tornarem campeões. Na Antigüidade, o grego competia, mas sua busca pela vitória fundamentava-se no superar-se, no romper barreiras individuais, para então alcançar o seu máximo na competição em que participava e assim aproximar-se de uma condição divina. A vitória sobre o adversário era uma decorrência desse processo. Para a sociedade grega helêni$\mathrm{ca}$, os vitoriosos seriam todos aqueles que superassem seus limites físicos e morais. O recorde (do inglês record, registro), com a idéia de valorização social, através dos dados numéricos, nasceu com o esporte moderno e se fortalece, cada vez mais, no esporte contemporâneo.

Mais fortemente, no século XIX, a valorização das marcas se fez presente no mundo esportivo e o recorde adquiriu uma importância excepcional. É característica desta sociedade mensurar a maior parte de suas atividades, dominadas pela ciência e pela tecnologia, que se reflete em transformar cada ação esportiva em uma medida quantificada. Para Cagigal(2) esta valorização do número salta da ciência em outras ordens da vida, da indústria, do comércio, da propaganda (...) $\dot{A}$ medida que o tempo invade a esfera esportiva, ai se impõe a marca, o recorde, como elemento essencial da apreciação do esporte, inclusive em níveis elementares (p. 586).

Assim, a prática esportiva, com o objetivo de atingir os melhores resultados dentro da competição, continua a firmar-se como um espaço de realização e de confirmação de competências pessoais e sociais, 
numa sociedade que valoriza o sucesso, a ascensão e a vitória( ${ }^{(1)}$. Além disso, a superação é tida como característica inerente do esporte, que se materializa na forma de recordes.

Hoje, a superação de marcas é um feito grandioso, merecedor de ampla divulgação pelos meios de comunicação de massa para todo o mundo. Muitos recordes que foram conquistados no início do século XX e considerados imbatíveis pelos próprios homens têm sido superados, ao longo do tempo, pelas mulheres. Estas marcas são quebradas quase todos os meses em alguma prova, e em qualquer modalidade esportiva. Uma das grandes motivações de qualquer atleta que participa hoje de importantes competições nacionais ou internacionais está não somente na vitória, mas justamente na luta pela conquista do recorde. Segundo Calderon (3) a luta do atleta não é tanto contra o adversário, "mas contra o cronômetro". E continua, o pior é que também os cronômetros estão melhorando (...) Há relativamente pouco tempo, os cronômetros mediam somente os décimos de segundo. Com a aparição dos cronômetros eletrônicos, se tem incorporado os centésimos e milésimos (...) e as marcas atuais são mais efêmeras que as de antes (p. 61).

Partícipe desta empreitada, o treinamento exerce importante papel como meio para este fim. A cada treino, metas vão sendo estabelecidas e, se no futuro próximo forem alcançadas, passado o amanhã, já estarão ultrapassadas. Assim, dia após dia, os atletas convivem e têm a possibilidade de descobrir um importante valor moral do esporte, o qual Coubertin referiu-se: o espírito de superação.

Esta busca incessante pelo sucesso e pela superação dos recordes pressupõe, de maneira muito acertiva, uma evolução material da sociedade e física do atleta. Como já mencionado, nos treinos diários o atleta busca a perfeição técnica, tendo em seu auxílio os estudos científicos sobre o movimento humano; já os fabricantes de materiais e equipamentos esportivos cumprem seu papel, lançando no mercado produtos sempre mais inovadores a intervalos cada vez menores. O mesmo se pode dizer sobre a evolução nas técnicas de construção de instalações esportivas. Conclui-se então que o recorde é o resultado de alguns fatores que se combinam num mesmo momento: o atleta atinge o melhor de sua técnica, reúne todas as suas virtudes físicas, aproveita-se dos recursos materiais que estão ao seu alcance e, excepcionalmente motivado, supera uma marca. Ou seja, o conjunto de fatores físicos e mentais, aliados à técnica e a tecnologia, contribuem indefinidamente para a construção de uma situação vitoriosa.

No esporte, as vitórias casuais são cada vez mais raras. Isso porque, afirma Cagigal (2) elas são resultado de um árduo trabalho realizado por um atleta em meio de um progresso geral (p. 523). Para elevar um centímetro ou reduzir centésimos de segundos em qualquer recorde são necessárias investigações científicas, aplicações técnicas e constantes esforços de adaptação pessoal a elas (p. 863). Observando esse processo dinâmico de descoberta das ciências aplicadas ao esporte para melhorar técnicas e tecnologias, faz-se necessário refletir sobre quais as razões que fazem homens e mulheres submeterem-se e prosseguirem em treinos diários norteados por conhecimentos científicos sem, porém, deixarem de apresentar um alto grau de exigência e dedicação aos praticantes. Tendo notado tão claramente o desenvolvimento tecnológico, Cagigal (2) questionou o quanto o progresso não visível, não tangível ao ser humano, evolui e afirmou: o atleta de alguma maneira se tem conquistado a si mesmo, tem desafiado e vencido, em parte, suas próprias limitações. Uma performance esportiva não se conquista sem um complexo desenvolvimento humano (p. 824).

É bem verdade que todo este esforço físico e mental do atleta para conquistar vitórias e recordes, quando alcançados, é premiado com um imenso prestígio e poder sociais, nacional e até internacionalmente. Some-se a isso a retribuição financeira, em forma de bonificações dos clubes e patrocínios, aumentando a sua condição econômica, favorecendo a inserção e manutenção em espaços sociais desejados desde muito, o que para alguns atletas se constitui como real sentido de vida(1,9). Eis aí uma das representações do imaginário esportivo atual.

Muito além da exigência excessiva imposta implícita e explicitamente pela sociedade, seja ela na forma de público que deseja ver o espetáculo, de patrocinadores que querem o vínculo de suas logomarcas com vencedores, do Estado que visa fortalecer a imagem, a qualidade de sua política como boa, ou pelo povo, que projeta, em um único indivíduo ou na equipe que se fazem seus representantes, os mais diversos sentimentos pessoais. Há um desejo latente desse 
público ver seus sonhos serem realizados na vitória e na conquista e recorde daquele que representa a superação de um limite individual e por vezes social. Raramente um homem ou uma mulher é capaz de superar marcas no esporte sem antes desenvolver em si este desejo desvinculado de fatores extrínsecos. As mudanças produzidas no ambiente esportivo ocorrem paralelas e inter-relacionadas com aquelas processadas na estrutura social. Sendo possível afirmar que indivíduos e sociedade caminham juntos na busca de conhecimentos científicos para a melhoria da prática esportiva almejando a vitória. Resta então uma pergunta: este progresso na obtenção de marcas representaria a verdadeira evolução humana?

Baseado em alguns autores (2, 3, 9, 16), a resposta será negativa se houver a intenção de submissão a quaisquer esforços, lícitos ou não, com o intuito de atingir apenas e tão somente metas e superar marcas.

Porém, poderá ser afirmativa se por meio deste exercício de superação de marcas o atleta praticar este ato também na sua vida, fora do ambiente esportivo. Quanto ao surgimento de novas técnicas e tecnologias, estas representarão progresso se auxiliarem, de maneira honesta e pedagógica na conquista do atleta. Essa discussão leva a um questionamento da palavra recorde que perdeu seu sentido original (registro) para ser no esporte contemporâneo um resultado complexo da superação de limites individuais e sociais.

\section{DOPING}

$\mathrm{Na}$ proposta original do Movimento Olímpico, os Jogos Olímpicos da Era Moderna seriam uma grandiosa festa, momento de confraternização entre os povos e de internacionalização do esporte, com o objetivo de popularizá-lo. Segundo Proença \& Constantino (16) o Movimento Olímpico reformador "entendia que o esporte tinha indiscutiveis potencialidades educativas e que generalizá-las era contribuir para uma sociedade mais saudável, logo mais desenvolvida" (p. 54). Porém, segundo estes mesmos autores, a frase de Coubertin "o mais importante nos Jogos Olímpicos não é ganhar, mas participar, tal como a coisa mais importante da vida não é o triunfo, mas a luta e, o essencial não é conquistar, mas ter lutado com dignidade" (p. 74) encontrase em desuso na atualidade. Assim, a afirmação "o importante não é vencer, é competir", feita em 1908, momentos antes do início dos Jogos de Londres, tor- nou-se tão anacrônica quanto o calçado esportivo usado por Spyridon Louis, o vencedor da maratona nos Jogos Olímpicos de 1896.

Vimos anteriormente, que a "vitória, e somente a vitória" mostra ser uma exigência do esporte contemporâneo, seguindo a tendência da sociedade atual, de caráter altamente quantitativo e competitivo. Estudos apontam que atletas de alta performance têm como perfil procurar tarefas desafiantes (10). Ogilvie \& Tutko (15), afirmam que os esportistas possuem também, entre outras características, elevada resistência psíquica, autodomínio e controle emocional. Entretanto, afirmações como estas podem ser questionadas, na medida em que cada indivíduo tem reações particulares conforme o que percebe de si mesmo, de suas capacidades e da importância pessoal dada à situação a enfrentar $(8,19)$. Questões como essas e afirmações como as de Meynaud (11) "não está provado que a confrontação esportiva discorra sempre em uma atmosfera de lealdade" (p. 227), levam as discussões sobre o doping a ocupar um espaço privilegiado no âmbito do esporte contemporâneo.

A origem da utilização do termo doping no esporte é contada por Cagigal (2) com a seguinte narrativa: $o$ termo doping (drogado) começou a ser usado nas corridas de cavalos, primeiro esporte em que se utilizou fármaco clandestinamente para conseguir que um determinado cavalo corresse mais lento e perdesse. Hoje este termo designa a ingestão de medicamentos usados por certos atletas para conseguir justamente o contrário: tentar ganhar (p. 824). Espera-se que uma competição seja pautada pela igualdade de oportunidades, baseada no desinteresse para além da competição em si mesma, onde vence o melhor, quem reúne mais competências e quem mais trabalhou para alcançar o resultado. Nem sempre essa expectativa se faz verdadeira no esporte: a utilização de substâncias dopantes e o seu refinamento, que leva à inviabilização de sua detecção, desvirtuam o sentido de igualdade que norteia a competição. O fair-play cede espaço ao vale tudo, que por sua vez reforça o uso de quaisquer recursos que viabilizem a obtenção da vitória. Essa é a lógica que tem prevalecido em grande parte nos altos círculos do esporte de rendimento.

Existem diferentes motivos competindo pelo comportamento do indivíduo, e aquele ao qual for atribuído maior significado passará a influenciar sua atitude. 
Uma visão que tem prevalecido no esporte é a de que as metas dos atletas se concentram na competição e na conquista de marcas sempre superiores. $\mathrm{O}$ corpo deste indivíduo é considerado somente um instrumento para conseguir estes fins (20). Isso vem ao encontro da proposta do esporte atual que privilegia a competição. Quando um atleta tem determinação por vencer a qualquer preço e a instituição e equipe que o cercam compartilham desse espírito, alguns excessos podem ser cometidos, fazendo com que valores éticos sejam preteridos. Assim, a auto-manipulação hormonal mostra-se como um meio eficaz para a superação dos obstáculos que se apresentam (12, 13). Há uma idéia no esporte de alto rendimento a respeito do perfil do atleta que busca substâncias proibidas: envolvido com o objetivo, o primeiro compromisso desse tipo de atleta é consigo mesmo, depois com os demais e por último, com o regulamento (3).

A razão física para o uso de drogas e, mais recentemente, para a remodelação genética (13) é melhorar o desempenho, dando-lhe um maior poder competitivo (1). A razão psicológica de dopar-se reflete em sua raiz um alto grau de exigência (intrínseca e extrínseca) e de responsabilidade. $\mathrm{O}$ atleta que utiliza estimulação artificial opta por esta conduta porque sente-se inseguro, acreditando não ser capaz de corresponder às suas expectativas e de muitas outras pessoas, ainda mais quando a sociedade atual tem como parâmetro produtivo a realização de resultados - e no esporte essa lógica é imediata e evidente. Além disso, quando um atleta faz uso de substâncias dopantes ele busca não somente a vitória e o prazer que esta lhe proporciona, mas o pareamento com retribuição financeira e prestígio social, já discutidos anteriormente.

Com o fim do amadorismo, o esporte converteu-se em um meio de vida, uma atividade profissional: homens de excepcionais dotes para a luta ou para a corrida passam a receber quantias volumosas comprometendo-se a determinadas atuações, e assim, ao longo dos tempos, os campeões do esporte têm sido transformados em verdadeiros produtos que são vendidos, negociados (18, 21). Os atletas de alto nível, igual aos demais profissionais destacados, permanecem em uma luta constante por sua posição; o que os diferencia, é que os atletas dependem unicamente de seu rendimento, o qual têm de maximizar em curtos períodos de tempo, pois geralmente, suas car- reiras são bastante curtas (7). Esse pode ser um dos argumentos utilizados para justificar máximas como "ganhar como for" e "a qualquer custo".

Os campeões são vistos como heróis positivos da sociedade e quando utilizam substâncias ilícitas para vencer, teme-se que estejam prejudicando a si mesmos e a própria imagem do esporte. É necessário refletir se os desvios que se cometem às potencialidades educacional e cultural do Esporte, proclamadas por Pierre de Coubertin, devem ser imputados apenas aos praticantes esportivos ou se a todos os agentes que intervêm neste fenômeno.

\section{DERROTA}

O ambiente esportivo altamente competitivo criou uma condição absoluta e inquestionável de valorização excessiva da vitória. Diante desta questão, Calderon (3) afirma que o motivo da prática do doping ter-se generalizado entre os atletas se deve a que no esporte-espetáculo somente há vencedores e vencidos, o que produz uma grande tensão. Ninguém quer pertencer à segunda categoria, ninguém quer ser um perdedor, pois a sociedade somente valoriza os ganhadores (p. 86). É certo que nas competições esportivas só há um primeiro lugar e a ele é destinado o título de vencedor. Quanto aos demais competidores, sejam eles segundo, terceiro, quarto ou último colocado, estes são os perdedores, os derrotados. Logo, nas competições esportivas há mais derrotados, do que vitoriosos. Já afirmamos que o esporte contemporâneo reflete em seu ambiente características da sociedade, como a importância da quantificação, do registro dos números e da valorização dos primeiros colocados. Porém, o número que se valoriza é aquele que representa a vitória, a superação das marcas, o registro do recorde. Assim, Cagigal (2) observa que nas grandes competições esportivas, não é freqüente elaborar estatísticas das derrotas famosas, muito menos de derrotas não famosas, lógicas, esperadas. Tal estatística não seria, naturalmente, sensacionalista, propagandística. Segundo os elaboradores de números, tais estatísticas não interessariam à sociedade (p. 453). Diante dessa afirmação surge outro questionamento: todos esses que não vencem, são na realidade derrotados?

Para Samulski (19), uma vitória não é idêntica a uma experiência de êxito, e uma derrota não é em si, uma experiência de fracasso. As experiências de êxito aparecem 
quando o rendimento esperado foi alcançado ou superado. As experiências de fracasso se encontram na diferença negativa entre o resultado esperado e o resultado obtido (p. 145). Diante do resultado obtido e comparando-o com o desejado, é aceitável o sentimento de frustração, raiva ou talvez, decepção do atleta quando não consegue atingir seu objetivo. Mas, o que se espera deste mesmo indivíduo é que ele aja para a superação da situação vivida naquele momento. Agir significa, nesse contexto, analisar e solucionar problemas e conflitos sociais. Portanto, faz-se necessário aprender a receber derrotas e a preparar-se para outras que possivelmente ocorrerão.

Os atletas de alto rendimento se apresentam com uma preparação física distinta da média da população, e têm ainda uma preparação mental igualmente excepcional. Para sagrarem-se campeões nas competições e vencer também os obstáculos que surgem ao longo de sua jornada esportiva, alguns deles lançam mão de vários artifícios psicológicos. Assim, a motivação, o pensamento positivo e a autoconfiança se fazem constantes no desafio de superar.

A motivação tem duas fontes: a extrínseca e a intrínseca. Pessoas com motivação intrínseca esforçam-se interiormente para serem competentes e auto-determinadas em sua busca de dominar a tarefa em questão (5). O indivíduo pode possuir inúmeras competências que o habilitem à realização de tarefas, porém a motivação determinará o grau de envolvimento e, muitas vezes, a qualidade com que a tarefa será cumprida (6).

A autoconfiança em ganhar influencia favoravelmente no esforço realizado, sendo que o contrário também é verdade, quando a pessoa mantém expectativas de perder. González (8) acredita que a importância de ganhar ou perder, em função de seu esforço na motivação interna, se deve à informação que proporciona sobre a habilidade ou competência sobre si mesmo. O êxito aumenta a autoconfiança individual, pode garantir a evolução social positiva e produzir um reconhecimento social favorável. Ao contrário, quando um indivíduo perde, seu fracasso indica que não é tão competente e não possui a capacidade requeri$d a$ (p. 127). Para que a autoconfiança esteja presente no atleta, o conhecimento sobre si e seu meio ambiente é essencial para a orientação sobre suas possibilidades e limites de uma ação, adaptada à situação (5). Weinberg \& Gould (22) descrevem a importância da autoconfiança na conquista da vitória e afirmam que os atletas confiantes acreditam em si mesmos. Mais importante, eles acreditam em suas capacidades de adquirir as habilidades e as competências necessárias, tanto psicológicas como mentais, para atingir seu potencial. A autoconfiança ideal significa estar tão convencido de poder alcançar suas metas que você lutará arduamente para atingi-las (p. 310).

Muitos atletas de alto nível motivam-se em situações estressantes de competição, mentalizando suas capacidades positivas. Desenvolver um pensamento positivo é muito importante para a realização de uma tarefa com sucesso.

Todos estes recursos utilizados em uma preparação psicológica fazem diferença no momento da competição, porém, a derrota é o lado oposto da questão quando se deseja apenas obter a vitória. Nem toda preparação física ou mental, a partir de treinamentos extenuantes, nem a utilização de conhecimentos científicos, nem de materiais feitos a partir de avançada tecnologia, muito menos o uso de substâncias dopantes, dão garantia ao atleta da vitória.

Ganhar depois de estar abatido, crer na possibilidade da vitória novamente, é decisivo para permanecer no esporte de alto rendimento. Assim, torna-se importante que os atletas de alto rendimento aprendam a não desistir imediatamente ou desanimar diante das dificuldades (8). Por isso, "saber perder" é uma das características que se atribui ao "estilo esportivo". Mais do que uma aceitação, acredita-se que este comportamento deve ser incorporado pelos atletas que desejam ser denominados campeões, visto que para atingir este posto eles terão que aprender a competir esportivamente, a assimilar as derrotas, superando-as ao longo da jornada.

Assim a derrota pode levar o atleta a desenvolver dois tipos de condutas: ou provoca o abandono da vida competitiva ou produz um fortalecimento de atitude. Afirma Cagigal (2) que das derrotas, do sentimento de inferioridade derivado delas, quando não cristalizam em frustração permanente, se produz na reorganização de forças pessoais; e aí está o princípio da superação. A derrota superada significa enriquecimento da pessoa. Em uma personalidade preparada, esta antítese desencadeia novas energias, descobre inusitadas habilidades, abre horizontes, ordena uma reestruturação de mecanismos, enriquece as diferenciações, de todo o qual sai a personalidade fortalecida (p. 844). 
As pessoas que defendem os benefícios do esporte no desenvolvimento do caráter afirmam que os atletas aprendem a superar obstáculos, a cooperar com os companheiros, a desenvolver autocontrole e persistir diante de derrota $(16,22)$. A prática esportiva surge como um espírito de superação de limites, e este estímulo para a superação constante por parte dos atletas é considerado como um ideal positivo para a formação das pessoas; daí a importância do esporte como agente socializador. Cagigal (2) nos faz refletir mais profundamente na questão, ao afirmar que "saber perder" e, como perspectiva educativa, "ensinar a saber perder" não significam necessariamente derrotismo nem fatalismo. Para o autor, os verdadeiros triunfadores na humanidade não são sempre vencedores, mas sim os que têm assumido plenamente sua condição humana (p. 843).

\section{CONSIDERAÇÕES FINAIS}

A convivência em sociedade presume a formalização e desempenho de vários papéis sociais. O que permite a convivência nos grupos é a existência de regras reconhecidas como justas e passíveis de cumprimento. Aos indivíduos cabe lutar pela sua manutenção ou transformação quando elas já não mais cumprirem uma função norteadora.

O papel que o atleta desempenha e as expectativas que a sociedade tem dele estão relacionados com a conquista de recordes, vitórias, triunfos, sempre com muita luta e honestidade. Esse rol de conquistas é o desejo de muitos atletas e da população média. É possível dizer que a superação se traduz na manutenção do desejo, na esperança de sua realização e na ação para a sua viabilização, e é esse conjunto de atitudes que levará o atleta a superar-se, cumprindo a função social de elemento de projeção por parte daqueles que buscam realizar esse tipo de sonho. Neste sentido, o atleta seria uma pessoa que é capaz de "perder melhor", visto que o ideal olímpico valoriza mais a participação do que a vitória. Porém, é desejável que as derrotas surgidas da confrontação esportiva não sejam irreparáveis, mas superáveis com a mesma vontade e desejo de luta que faz do atleta um herói.

Ao atleta é necessário ser capaz de conviver e entender que no esporte sempre haverá a dualidade: em alguns momentos, o prestígio baixo, a lesão, a derro- ta, a falta de patrocínio e em outros a glória produzida pela vitória.

A interiorização desse preceito cabe não só aos atletas que a qualquer preço procuram atingir o topo, mas ao próprio público, aos dirigentes e patrocinadores que, pelas suas exigências - implícitas ou não -, contribuem para que o esporte, e não somente o esportista, tenha a sua imagem denegrida. Numa época onde a valorização dos resultados sufoca os seres humanos, a aceitação de limites individuais é a maior prova de superação que um indivíduo pode proporcionar a si próprio.

\section{CORRESPONDÊNCIA}

\section{Katia Rubio}

Núcleo de Estudos em Pesquisa Social

do Movimento Humano

Escola de Educação Física e Esporte

Universidade de São Paulo

Avenida Professor Mello de Moraes, 65

CEP 05508-900 Cidade Universitária

São Paulo, SP, Brasil

katrubio@usp.br 


\section{REFERÊNCIAS BIBLIOGRÁFICAS}

1 Brohm, J.M.; Bourdieu P.; Dunning, E.; Hargreaves, J.; Todd, T.; Young, K. (1993). Materiales de Sociologia del Deporte Genealogia del poder. Madrid: Lãs Ediciones de La Piqueta.

2 Cagigal, J.M (1996). José Maria Cagical: obras selectas. Madrid: Comité Olímpico Español.

3 Calderon, E. (1999). Deporte y limites. Madrid: Grupo Anaya.

4 COI (2001). Carta Olímpica. Lausanne: Comitê Olímpico Internacional.

5 Chirivella, E.C. (1999). Motivación y su aplicación prática al deporte. Valencia: Promolibro.

6 Escartí, A.; Cervelló, E. (1994). La motivación en el deporte. In: I. Balaguer (Ed) Entrenamiento psicológico en el deporte. Valencia: Albatros, 146-159.

7 González, J. D.; Ferrando, M.G.; Rodríguez, M. L. (1998). El deporte mediático y la mercantilización del deporte: la dialéctica del deporte de alto nível. In: M. G. Ferrando, N P. Barata, F. L. Otero (orgs.) Sociología del Deporte. Madrid: Alianza Editorial.

8 González, J. L. (1997). Psicologia del Deporte. Madrid: Editora Biblioteca Nueva.

9 Marivoet, S. (1998). Aspectos sociológicos do desporto. Lisboa: Livros Horizonte.

10 Martin, G. L. (2001) Consultoria em Psicologia do Esporte: orientações práticas em análise do comportamento. Campinas: Instituto de Análise do Comportamento.

11 Meynaud, J. (1972). El deporte y la política. Barcelona: Editorial Hispano Europa.

12 Miah, A. (2003) Olympic athletes and science: Ethics and possibilities for improvement. Paper presented to the $6^{\text {th }}$ Joint International Session for Educators \& Officials of Higher Institutes of Physical Education, Olympia, Greece, June.

13 Miah, A. (2003) Genetically modified athletes: Biomedical ethics, gene doping and sport. London and New York: Routledge.

14 Müller, N. (ed.) (2000) Pierre de Coubertin 1863-1937: Olympism Selected Writings. Lausanne: Comitê Olímpico Internacional.

15 Ogilvie, B.; Tutko, T. (1971). Sport: if you want build character try something else. Pshychology Today, 10, 61-63.

16 Proença, J.; Constantino, J.P. (1998). Olimpismo, desporto e educação. Lisboa: Edições Universitárias Lusófonas.

17 Rubio, K. (2001). O Imaginário esportivo: o atleta contemporâneo e o mito do herói. São Paulo: Casa do Psicólogo.

18 Rubio, K. (2002) O trabalho do atleta e a produção do espetáculo esportivo. Revista Eletrónica de Geografia y Ciências Sociales, Vol. VI, 119(95). Universidad de Barcelona.

19 Samulski, D. M. (2002). Psicologia do esporte. São Paulo: Editora Manole.

20 Rodriguez, E.L. (1987). La Sociología del Deporte y el estudio de la cultura contemporanea: observaciones en torno a la difusion de nuevos deportes. In: J. L. G. Fernández (Ed.) Sociologia del Deporte. Bilbao: Editorial Universidad del Pais Vasco, 6-22.

21 Thomas, R.; Haumont, A.; Levet, J. L. (1988). Sociologia del Deporte. Bellaterra: Ediciones Bellaterra.

22 Weinberg, R. S, Gould, D. (2001). Fundamentos da Psicologia do Esporte e do Exercício. Porto Alegre: Artmed Editora. 